\title{
Sentidos e significados do trabalho: dos impedimentos às possibilidades do trabalho de pessoas com deficiências
}

\section{Sense and meanings of work: the impediments and the job possibilities for people with disabilities}

\section{Los sentidos y significados del trabajo: de los impedimentos a las posibilidades de trabajo para personas con discapacidad}

\author{
Juliana Cavalcante Marinho Paiva* \\ Universidade Federal do Rio Grande do Norte - UFRN, Rio Grande do Norte, Brasil \\ Pedro Fernando Bendassolli** \\ Universidade Federal do Rio Grande do Norte - UFRN, Rio Grande do Norte, Brasil
}

\section{Camila Costa Torres***}

Universidade Federal do Rio Grande do Norte - UFRN, Rio Grande do Norte, Brasil

\begin{abstract}
RESUMO
O objetivo deste estudo foi compreender a relação das pessoas com deficiências e seu trabalho. Especificamente, buscou-se identificar os sentidos e significados atribuídos ao trabalho, e descrever os impedimentos da atividade concreta e as estratégias desenvolvidas para sua superação. Esse objetivo é inspirado na perspectiva teórica sócio-histórica e nas teorias da atividade, clínica da atividade em particular. A pesquisa foi realizada com 16 servidores de uma Instituição de Ensino Superior - IES, tratando-se de um estudo multi-métodos sequencial, transversal de orientação qualitativa, com utilização de técnicas de entrevista narrativa e criação fotográfica. Os resultados demonstraram o trabalho sendo caracterizado como uma necessidade, fonte de prazer, reconhecimento, socialização. Os impedimentos estiveram mais relacionados às condições ambientais da atividade, do que propriamente à condição da deficiência. Conclui-se que o acesso ao trabalho é uma importante ferramenta de inclusão social de pessoas com deficiência, e, nesse sentido, leis de reserva de vaga cumprem seu papel.
\end{abstract}

Palavras-chaves: trabalho, deficiência, reserva de vagas.

\section{ABSTRACT}

The objective of this study was to understand the relationship between people with disabilities and their labor. Senses and meanings related to work were specifically identified; also describing the impediments of concrete activities, as well the strategies developed for overcoming them. This objective is inspired on the social historic theoretical perspective as well as on the activity's theory, specifically in the activity clinic approach. The 
research has been made possible through the interview of 16 workers from a IES, it categorizes as a multi-method sequential and transversal study of qualitative orientation, making use of technics of narrative interviews and photographic creation. The results indicate that work was described as a necessity, a source of pleasure, recognition and socialization. Impediments were more deeply related to the physical conditions of the work environment than to the person's disabilities. Conclusion points out that the access to work, acts as a social inclusion tool for peoples with disabilities, and showing that, the laws regarding quota reservations fulfill their objective.

Keywords: work, disabilities, quota.

\section{RESUMEN}

El objetivo de este estudio fue entender la relación de las personas con discapacidad y su trabajo. Concretamente, fue identificado los sentidos y significados asignados al trabajo, describir las restricciones de su actividad concreta, y las estrategias desarrolladas para superarlos. Este objetivo se inspira en la perspectiva teórica socio histórica y las teorías de la Actividad, clinica de la actividad en particular. La investigación se realizó con 16 servidores de una institución de educación superior, es un estudio "multimétodos", secuencial y transversal, de orientación cualitativa con el uso de las técnicas de entrevista narrativa y creación fotográfica. Los resultados mostraron que el trabajo se caracteriza por ser una necesidad, una fuente de placer, reconocimiento y socialización. Las restricciones se relacionan más a las condiciones ambientales de la actividad que la condición de discapacidad. La conclusión es de que el acceso al trabajo permite una importante herramienta para la inclusión social de las personas con discapacidad, y en este sentido, la leye de vacantes reservados cumple su papel.

Palabras-clave: trabajo, discapacidad, vacantes reservados.

\section{Introdução}

A deficiência existe desde o surgimento do homo sapiens, e as evidências históricas, pinturas rupestres, e até os primeiros escritos, confirmam essa afirmação (Silva, 1987). Alguns exemplos do interesse da psicologia por essa temática podem ser localizados nos trabalhos de Binet (1857-1911), no início do século XX, e nos de Vygotsky (1924/2011), com a proposta de disciplina por ele denominada "defectologia". Ao levar em consideração a formação social da mente, Vygotsky afirmava que a criança "defeituosa" não sentia diretamente seu defeito: sua percepção advinha das dificuldades enfrentadas, e, principalmente, da existência de um padrão de normalidade imposto pela sociedade não deficiente.

Várias mudanças históricas ocorreram desde os estudos de Vygotsky (1924/2011) sobre deficiências. Por exemplo, a atenção especial dada ao assunto no âmbito dos Direitos Humanos, e a emergência do movimento da inclusão social (Carvalho-Freitas, 2007; Figueira, 2008). Esse movimento de inclusão visava não apenas à melhoria de condições de vida de pessoas com deficiências, mas a diminuição do 
estigma de "incapaz" ou "inferior" presente em alguns discursos circulados pela sociedade ao longo do tempo. A partir da década de 1990 , os estudos sobre a deficiência ampliaram-se para os mais diversos campos teóricos, com enfoque em várias perspectivas, como na da inclusão.

Em termos conceituais, as pessoas com deficiências são as que apresentam significativas diferenças físicas, sensoriais ou intelectuais, decorrentes de fatores congênitos ou adquiridos, de caráter permanente, e que acarretam dificuldades e incapacidades em sua interação com o meio físico e social (e.g.: Ciszewski, 2005; Sassaki, 2002).

Os dados do Instituto Brasileiro de Geografia e Estatística - IBGE, relativos ao censo de 2010, retratam um cenário em que $24 \%$ da população brasileira declarou possuir pelo menos uma das deficiências investigadas (intelectual, motora, visual e auditiva). E, comparativamente, houve muitas diferenças entre a população com e sem deficiências. Por exemplo, os rendimentos salariais diferem: o grupo das pessoas sem deficiências é mais bem remunerado e tende a regimes formais de trabalho (carteira assinada) (IBGE, 2010). Visando, entre outras coisas, a reversão desse quadro de desigualdades, o Governo Brasileiro criou diversas leis federais, tais como a lei no 8.213 art. 93 (1991), que garante vagas reservadas à população com deficiências em toda empresa com mais de 100 empregados.

Passados mais de vinte anos desde que a referida lei entrou em vigor, e embora tenha havido sinais positivos de mudanças, há ainda impedimentos para que a inserção laboral seja plenamente efetuada (Zanitelli, 2013). Estudos apontaram que as principais dificuldades de inserção nas empresas são a falta de equipamentos para atender às necessidades especiais, a ausência de acessibilidade, a máqualificação profissional e o desconhecimento, por parte dos gestores, das capacidades laborais das pessoas com deficiências (e.g.: Brunstein \& Serrano, 2008; França \& Pagliuca, 2009; Monteiro, Oliveira, Rodrigues, \& Dias, 2011).

Nesse contexto, investigar a relação das pessoas com deficiências e o trabalho, especificamente em função da aplicação da Lei no 8213 (1991), é um modo de compreender o fenômeno da inclusão e de contribuir para a integração efetiva dessas pessoas nos espaços laborais. Considerando a centralidade do trabalho na constituição do próprio sujeito, compreender aquela relação traz ainda subsídios para se articular ações voltadas a esse público por parte da psicologia do trabalho e das organizações. Na sequência, exploramos essa questão.

\section{Trabalho, atividade e sentido}


O trabalho consiste de uma atividade por meio do qual o homem atua sobre a natureza, a transforma e submete a seus interesses, garantindo sua subsistência e o próprio ambiente cultural em que vive (Marx, 1867/1983). Essa natureza psicossocial do trabalho foi explorada por diversos autores e correntes, entre eles os vinculados à perspectiva sócio-histórica em psicologia, particularmente na vertente aberta por Vygotsky (1896/2008) e Leontiev (1978).

Antes de ser "sujeito", o ser humano é social (Vygotsky, 1896/2008), e esse sujeito se constitui na relação dialética com o meio social, na e pela atividade. $\mathrm{Na}$ atividade, o homem revela o caráter histórico, as relações sociais, o modo de produção e, ao mesmo tempo, expressa sua singularidade, o que de novo é capaz de produzir, os significados sociais e os sentidos subjetivos (Aguiar \& Ozella, 2006). Assim, a linguagem possui papel fundamental como mediador do processo de constituição do sujeito humano, por meio do processo de significação (produção de sentidos e significados). Apesar de serem termos comumente utilizados como sinônimos no senso comum, são tratados aqui como conceitos distintos. Para a perspectiva sócio-histórica, apesar de diferenciados, fazem parte de uma mesma totalidade (Namura, 2004). Vygotsky (1896/2008) admite que cada construto refere-se a uma dimensão diferente: enquanto o significado é coletivo, o sentido é pessoal.

Nessa perspectiva, os sentidos estão intimamente ligados a processos afetivos, os quais matizam a relação entre o pensamento e a linguagem, e presidem às escolhas que levam o pensamento a se objetivar em certos arranjos linguísticos ou semióticos. São, portanto, mais fluidos quando comparados aos significados (Barros, Paula, Pascual, \& Ximenes, 2009; Smolka, 2004). Para Vygotsky: "O sentido é um fluido dinâmico, e uma formação complexa com diversas zonas que variam em sua estabilidade. O significado é apenas uma dessas zonas de sentido que a palavra adquire no contexto da fala. É a mais estável, unificada e precisa dessas zonas" (1987, p. 465-466). Os significados referem-se a narrativas socialmente disseminadas, a imagens, representações, repertórios disponíveis em uma determinada época e sociedade.

Os sentidos e significados do trabalho são estudados por muitos autores, inclusive por pessoas com deficiências (e.g.: Pereira, Del Prette, \& Del Prette, 2008; Brunstein \& Serrano, 2008). Existe uma extensa literatura sobre o tema, bem como ampla variedade de perspectivas teóricas. Por exemplo, uma das vertentes amplamente disseminada no Brasil é a desenvolvida pelo grupo de pesquisadores que vieram a ser conhecidos como Meaning of Work Research Team, ou MOW (1987). Nesse modelo, o significado (que não se distingue de sentido) é uma cognição social e, como tal, é influenciada pela socialização, pelas experiências no mundo do trabalho, por aspectos de personalidade e por fatores socioeconômicos mais amplos. O MOW 
desmembra o significado do trabalho em algumas dimensões centrais, notadamente: sua centralidade (referindo-se à importância, absoluta e relativa do trabalho na vida de uma pessoa); as normas sociais relativas ao trabalho (direitos e deveres); e as expectativas com sua realização (resultados valorizados do trabalho). Esse modelo e perspectiva ensejou diversos estudos na psicologia do trabalho no país (e.g.: Borges, 1999). Deixou, como legado, a concepção do significado como uma cognição dinâmica, compartilhada socialmente e multifacetada.

Outra vertente, buscando diferenciar-se da anterior (embora a incorporando), propõe o estudo dos sentidos (como distinguidos de significados, mas não articulados a estes - como se verá na perspectiva sócio-histórica). Um exemplo é Morin (2006, 2007). Essa autora, que inspirou pesquisas no Brasil (e.g., Tolfo \& Piccinini, 2007), define o sentido como derivado da vivência ou experiência de coerência entre o sujeito e o trabalho que realiza. Baseada em uma perspectiva fenomenológica-existencial, Morin propõe que o sentido do trabalho é composto por uma dimensão mais cognitiva (representações do trabalho), por outra relativa à orientação (o que se busca na realização do trabalho), e pela dimensão de coerência self-trabalho. Assim, para Morin, o trabalho que "tem sentido" é aquele no qual o sujeito percepciona e vivencia determinadas características, com o fato de ele ser moralmente correto, útil à sociedade, permitir o desenvolvimento e autonomia dos sujeitos, entre outras.

Já na perspectiva sócio-histórica, base teórica principal deste artigo, sentidos e significados são teorizados no contexto da atividade concreta realizada pelo sujeito. Tal perspectiva esteve na origem do que vieram a ser conhecidas como teorias da atividade (Bendassolli, 2012). A compreensão de trabalho nessas teorias é ampla e diversificada, embora preservem a natureza mediatizante do trabalho e sua inscrição social, histórica e cultural. Uma ramificação das teorias da atividade é de especial interesse neste artigo, tendo em vista sua contribuição para as análises que serão propostas. Trata-se da perspectiva da clínica da atividade (Clot, 2008). Nela, parte-se da distinção essencial, proposta na ergonomia (e.g.: Wisner,1996), entre tarefa e atividade. Enquanto a primeira refere-se às prescrições impostas ao sujeito para dar conta do modo correto de realizar o trabalho, a atividade refere-se ao que é efetivamente realizado.

Tomando como base essa dicotomia entre a atividade prescrita e atividade real, ou entre tarefa (atividade prescrita) e atividade (atividade real), Clot (2008) propõe pensar numa terceira dimensão: o real da atividade. Este envolve o que foi prescrito, o que foi realizado, o modo como foi realizado, mas também o que não foi realizado, o que, de certa maneira, foi impedido de se realizar (Clot, 2010). Os impedimentos da atividade referem-se às circunstâncias ou 
situações nas quais o real da atividade não pode revelar-se ao sujeito em suas potencialidades. Por exemplo, quando o prescrito impede a inventividade, o desenvolvimento de novas formas de se fazer 0 trabalho. Ou então quando a atividade realizada, pelo fato de não englobar todo o domínio do real (Clot, 2008), "compete" com as atividades possíveis, suspensas, antecipadas, mas não realizadas. A superação dos impedimentos da atividade, para a clínica da atividade, está ligada ao desenvolvimento psicológico do sujeito e da própria atividade (poder de agir).

Este artigo se circunscreve no quadro mais amplo da perspectiva sócio-histórica e da clínica da atividade. Entendemos por "atividade" um contexto no qual o sujeito se apropria do mundo (internalização) e constrói seu próprio mundo para viver (externalização, produção dos sentidos). Tomamos especificamente o conceito de atividade proposto por Clot $(2008,2010)$. Nele, a atividade possui uma dimensão pessoal (projetos, desejos, sentidos), impessoal (o prescrito), interpessoal (as relações), e transpessoal (referindo-se a um gênero profissional). Inspirado em Vygotsky, Clot assume o caráter mediado e mediatizante da atividade, e a centralidade dos processos de significação, tanto para o "acesso" ao sujeito como à atividade ela própria - e isso sem prescindir dos aspectos objetivos da atividade (ferramentas, objetos, contexto).

Circunscrito nos domínios teóricos acima aludidos, objetivo deste artigo consiste em investigar a relação das pessoas com deficiências e seu trabalho, em particular no que diz respeito aos processos de construção e atribuição de sentidos e significados. Este objetivo se desdobra em dois outros específicos, quais sejam: identificar, ao longo da biografia profissional, os sentidos e significados atribuídos ao trabalho, e o modo como eles se relacionam com a percepção de deficiência; e descrever os impedimentos da atividade de trabalho real (concreta) vivenciados pelas pessoas com deficiências, e as estratégias desenvolvidas para sua superação.

\section{Método}

Trata-se de uma investigação de tipo multimétodos sequencial, transversal (Creswell, 2007), de orientação qualitativa e dividida em duas etapas. A primeira envolve a utilização de entrevista narrativa; e a segunda, a utilização de recurso fotográfico. A opção por utilizar essas duas estratégias, no contexto do tema deste artigo, fundamenta-se na necessidade de ir além do registro puramente linguístico, quer dizer, de uma postura que associa sentidos e significados exclusivamente à linguagem. Ao introduzir um mediador "concreto" (as fotos), abre-se a oportunidade de captar aspectos da atividade real, do fazer concreto do sujeito, e, tendo em vista um dos 
objetivos da pesquisa da qual derivou este artigo, isso permite captar a dinâmica real dos impedimentos da atividade e suas estratégias de superação.

\subsection{Participantes}

Participaram desta pesquisa servidores de uma instituição de ensino superior, ingressantes na instituição pelo sistema de reserva de vagas, conforme regulamentado pela lei no 8.213, art. 93 (1991). Como a referida lei se restringe a servidores técnico-administrativos, apenas estes foram considerados nos critérios de inclusão. O segundo critério era de que estivessem lotados no campus central da instituição. Na prática, os participantes foram acessados por meio de sites mantidos pelas instituições responsáveis tanto pela seleção e realização do concurso público, como pela divulgação dos resultados. Tratam-se de sites de conhecimento público. Com essa exploração, chegou-se a um universo composto por 28 servidores técnicoadministrativos.

Considerando esse universo, o próximo passo consistiu na divulgação da pesquisa junto a esse público. Por meio de parceria com a instituição-campo desta pesquisa, foi enviada uma carta-convite, aberta a todos os servidores, na qual se explicava os principais aspectos da pesquisa, e cuja resposta dos que se encaixassem nos critérios de participação poderia ser endereçada aos pesquisadores. Sem mais respostas por esse meio, foi então realizada uma divulgação presencial. Novamente em acordo com a instituição e os respectivos gestores, foram realizadas visitas nos diversos locais de trabalho da instituição. Nessas visitas, eram consultados os potenciais participantes sobre a ciência da carta enviada anteriormente, e sobre o interesse em participar da pesquisa. Considerando ambos os procedimentos, chegou-se ao número final de 16 participantes, com os quais se realizou a coleta das informações. O processo foi realizado nos termos das exigências éticas pertinentes e aprovado pelo Comitê de Ética em pesquisa, bem como pelo responsável pela gestão de pessoas da instituição.

\subsection{Técnicas de coleta de dados}

A entrevista narrativa, primeira estratégia utilizada, consiste em fazer a pessoa relatar algum acontecimento importante de sua vida e sobre seu contexto passado e atual, discorrendo livremente com incentivo do pesquisador, baseado numa questão disparadora. No processo da narrativa incluem-se representações da experiência vivida, tais como: atribuir sentidos, contar, analisar, interpretar (Galvão, 2005). A escolha das questões foi orientada pela revisão de literatura, por meio de adaptações de questionamentos em estudos de Morin (2001) 
e Graf e Coutinho (2011), acrescentando um questionamento acerca das dificuldades no trabalho, e servindo como mote a investigação dos impedimentos do trabalho tal como proposto por Clot (2008).

A técnica da entrevista narrativa se mostra coerente com os aportes teóricos adotados no estudo, enfatizando o processo de compreensão dos sentidos e significados construídos ao longo da história profissional do sujeito e no contexto de realização de sua atividade. Adicionalmente, a fim de complementar a investigação e ajudar a explicitar possíveis impedimentos à realização da atividade, bem como as potenciais estratégias de superação, foi também utilizada, como segunda estratégia de coleta, a produção fotográfica.

A fotografia, como forma de coleta de dados, é antiga, tanto na psicologia, como nas ciências sociais (Maurente \& Tittoni, 2007). Nesta pesquisa, a criação fotográfica consistiu da utilização da fotografia como instrumento que permitiu ao participante colocar-se na posição de observador de sua própria atividade, na medida em que, como se relata a seguir, cada participante pôde, após a tomada das fotos, falar sobre sua atividade, o que permitiu aos pesquisadores investigar a dialética entre sentidos-significados, os quais fazem parte inerente da atividade e do "falar sobre" essa atividade (Osório \& Maia, 2010). Tal estratégia permitiu, ainda, evidenciar o real da atividade, com os impedimentos concernentes a ele $e$ suas possibilidades de superação.

Resumidamente, a técnica da criação fotográfica foi realizada com a instrução, dada ao final da entrevista narrativa, para que o participante, munido de câmera fotográfica (ou um celular), escolhesse tanto alguns aspectos positivos como negativos de sua atividade e os registrassem. Não havia impedimentos em termos de quais fotos tirar ou não, a menos que isso fosse explicitamente colocado pelo gestor de cada participante. O próprio participante, nos termos que regem a privacidade de sua atividade, era livre para ponderar sobre quais situações podiam e quais não podiam ser fotografadas, uma vez que, posteriormente, tais fotos seriam comentadas na relação pesquisador-pesquisado. Portanto, dentro do permitido, o participante era para escolher as cenas, situações, objetos, configurações (ambiente de trabalho) que, na sua própria concepção, melhor representassem ou materializassem sua atividade (em termos de aspectos positivos e negativos). Na próxima seção apresentamos o modo como as fotos foram trabalhadas.

Em termos gerais, foi realizada uma média de quatro atividades com cada participante. O procedimento-padrão consistia, primeiramente, na disponibilização do Termo de Consentimento Livre e Esclarecido, para que o participante pudesse ler e assinar, dando anuência formal ao processo, em conformidade aos procedimentos exigidos pelo comitê de ética em pesquisa, cujo estudo foi submetido e aprovado (protocolo 422.284). Após a entrevista narrativa, seguia-se o 
encontro para validação da mesma e explicação do procedimento de criação fotográfica, para posterior encontro de apresentação das fotografias e elucidação dos motivos de sua escolha. $O$ procedimento era finalizado com um último encontro de fechamento.

\subsection{Procedimentos de análise de dados}

O método de análise e interpretação da entrevista narrativa iniciou-se com base em adaptações às proposições de Schütze (2007), organizado de acordo com as seguintes fases: transcrição detalhada do material verbal; divisão do texto em material indexado (quem fez o que, quando, onde e por quê), e material não-indexado (relativo a valores, juízos, sentimentos, conhecimento prático, sabedoria de vida). O material não indexado foi organizado e analisado a partir da técnica dos núcleos de significação. Estes, de acordo com Aguiar e Ozella (2006, 2013), consistem de estratégia para compreensão dos sentidos e significados presentes nos discursos, embora aqui adaptados para análise de narrativas.

Já o processo de análise das fotografias começou durante o próprio processo investigativo, a partir da elucidação dos motivos de escolha das fotografias. As novas narrativas eliciadas pelas fotografias foram analisadas evidenciando os núcleos de significação contidos (Aguiar \& Ozella, 2006, 2013). Ao final do processo fotográfico, alcançou-se o número de 58 fotografias. Os procedimentos de análise foram integrados de modo complementar, caracterizando temporalmente a história de vida em relação ao trabalho de cada participante. A entrevista estava voltada aos acontecimentos do passado da história da pessoa, enquanto a criação fotográfica se centrou nas situações presentes da atividade de trabalho.

\section{Resultados e discussão}

São apresentados, em primeiro lugar, quatro núcleos de significação centrais elaborados a partir das entrevistas. Tratam-se de "zonas de sentido" criadas pela linguagem dos sujeitos, isto é, cristalizações de aspectos da ordem mais ampla dos sentidos. Trechos das entrevistas são citados como ilustração das ideias nucleares envolvidas. Em segundo lugar, são descritos resultados das estratégias de fotografar aspectos da atividade de trabalho. Ambas as estratégias nos permitem discutir os sentidos-significados e os impedimentos/superações da atividade.

\subsection{Núcleos de significação}


O primeiro núcleo de significação encontrado em praticamente todas as entrevistas descreve o trabalho como uma necessidade, como forma de sobreviver. Essa forma de atribuir sentido ao trabalho já foi reportada em pesquisas na área (e.g., Borges, 1997; Soares, 1992). Algumas frases dos participantes ilustram esse ponto.

(...) você cresce e tem que ter alguma forma de garantir meios de se sustentar e de viver. Não pode viver eternamente preso, e dependente de outras pessoas (P1)

Mas o emprego é o alicerce da sua vida, ele define quem você é, os círculos que você frequenta. É onde você vai conhecer as pessoas que vão interagir com você é onde você vai ter seus círculos de amizade, seus círculos de conhecimento, tudo isso que vai acontecendo, define isso. Além do mais ele vai dar sua potência financeira. O trabalho não define quem você é, mas Ihe dá base para você ser quem você quer ser (P2)

A necessidade do trabalho está vinculada ao dinheiro. $E$, apesar de o trabalho significar, para P1 e P2, a necessidade do dinheiro para a subsistência, eles atribuem sentidos próprios ao expressar o motivo dessa necessidade. No caso do P1, é a "compra" sua liberdade de ser alguém, de ter uma individualidade e de não ser dependente de outras pessoas; no caso do P2, é a possibilidade de ele ser quem ele quiser.

O segundo núcleo, intimamente relacionado com o primeiro, apresenta o trabalho como algo associado ao prazer, capaz de propiciar a sensação de realização profissional. Os relatos, exemplificados a seguir, revelam a dimensão do prazer pela atividade e pelo trabalhar.

E se eu trabalhasse por hobbies eu seria talvez enfermeiro [sua profissão]. Porque é a profissão que eu conheço e é uma profissão que me dá muito prazer ... gostei muito do que eu fiz. Acho que por isso que eu consegui fazer bem e crescer na profissão, porque acho que quando a gente gosta do que faz, a gente faz bem e quando a gente faz bem tem sempre alguém para olhar e reconhecer. (P1)

Quando eu me identifico com a atividade, eu venho com prazer, não tenho nenhum problema. ... Não tenho problema, graças a Deus! Com um ambiente de trabalho tranquilo, prazeroso, faz ser prazeroso trabalhar. (P3)

As afirmações de P1 e P3 exemplificam algumas características do trabalho prazeroso. Durante as narrativas, esses participantes comentaram que gostam do que fazem, mas o gostar do trabalho não 
é restrito à tarefa, ao fazer prescrito, mas abrange os relacionamentos interpessoais, o reconhecimento, o salário. O sentido de prazer atribuído ao trabalho pelo $\mathrm{P} 1$ está baseado na sua percepção de que suas características pessoais se assemelham ao que é exigido pela tarefa. Já o participante três (P3) apresenta a profissão de enfermeiro como uma atividade que ele faria, ainda que não dependesse financeiramente dela, e atribui um sentido positivo ao relacionar a atividade bem feita com o reconhecimento por parte dos chefes, colegas e a própria sociedade. Como afirma Clot (2001, 1999), o trabalho bem feito está associado à própria saúde do trabalhador, estimulando, indiretamente podemos dizer, o próprio gostar do trabalho.

Pode-se então constatar, a partir dos sentidos e significados atribuídos por P1 e P2, que quando há um reconhecimento da condição de bom trabalhador, quer seja pelos pares, ou pelos chefes, há também a colocação desse trabalhador numa posição satisfatória e prazerosa com o trabalho. E o contrário também é verdadeiro, de modo que o não reconhecimento do trabalho (independente do motivo) coloca o trabalhador em uma condição de desprazer.

Deficiência, limitação e trabalho fizeram surgir nos relatos um terceiro núcleo de significação - núcleo esse relacionado à ideia de superação.

Superar limites é ótimo... E eu acho que o deficiente fica muito feliz de ver que uma pessoa não consegue fazer e ele consegue, é um prazer imenso você ter uma limitação e conseguir o que todo mundo acha que você não vai conseguir, e até mesmo você acha que não vai conseguir (...). (P4)

O sentido atribuído ao trabalho como superação, na fala do P4, está baseado na sua percepção de que consegue realizar tudo o que outras pessoas realizam, especialmente nas situações de trabalho. Com isso, ela atribui sentidos que relacionam o fato de conseguir fazer tarefas específicas, ainda que de seu jeito e ritmo próprios, em situações que ela não imaginava que conseguiria (como é o caso do trabalho).

No aspecto físico, eu tenho uma atrofia muscular. Psicologicamente falando, eu não me sinto mais deficiente. Eu comecei a pensar assim: que nessa vida ninguém é perfeito. Todo mundo tem seus medos, traumas, limitações. (P5)

Em várias situações, ao longo de sua história profissional, o P5 conta como o trabalho significou a superação de seu próprio estigma de "deficiente", e tal superação foi motivada pela atribuição de novos sentidos à sua percepção acerca das pessoas: ele passou a acreditar 
que todos possuem limitações e medos que fazem, das pessoas, seres humanos.

Outro núcleo de significação presente em nas narrativas foi a concepção de que trabalhar no serviço público representava a garantia de uma segurança e estabilidade, sendo esse o principal objetivo e sentido do trabalho concursado entre os participantes. Os relatos de P9 e P1 enfatizam tal significação.

Essa questão de trabalhar no serviço público tranquiliza. A questão da estabilidade, de você achar que dali você só sai se você quiser mesmo, ou se fizer besteira. Eu não tenho essa preocupação de chegar para trabalhar hoje e estar com uma carta de demissão amanhã, acho que a vantagem do serviço público é essa. Estabilidade. (P9).

Aí quando eu passei aqui as coisas mudaram pra melhor. Dá uma tranquilidade maior. Sei que tenho estabilidade. Apesar de não ser uma estabilidade definitiva, porque tem o estágio probatório, mas é uma estabilidade porque tem menos pressão. Diferente da empresa privada. (P1).

Em ambos os relatos, a busca pela segurança e estabilidade advém do contraste com a realidade das empresas privadas. Para o P9, o fato de ele poder exercer sua vontade própria no trabalho, sem risco de demissão ou retaliação, é motivo de atribuição de um sentido positivo a tal estabilidade. Ele não está à mercê das vontades dos outros, como nas empresas privadas.

As narrativas, no que diziam respeito ao trabalho no serviço público, mostram que há uma busca por uma posição estável, na tentativa de exercer a posição de trabalhador pelo maior tempo possível. De acordo com Furtado (2003), a sensação de estar excluído do mercado de trabalho formal, ou da possibilidade de vi-lo a ser, é psicologicamente desgastante para os trabalhadores, de modo que eles buscam alternativas que garantam a continuidade do trabalho, fazendo-os priorizar o trabalho no setor público, mesmo em detrimento de outras características, como o salário. Então, a exclusão do mercado de trabalho vai para além da preocupação com a renda ou subsistência, e refere-se ao próprio sentido de estar desempregado e de todos os estigmas referentes a essa situação. Embora não seja específico de pessoas com deficiências, a insegurança laboral pode ter um sentido diferente para pessoas que têm dificuldades em trabalhar devido à própria deficiência, aumentando sua vulnerabilidade.

\subsection{Criação fotográfica}


Como mencionado, as fotografias serviram para caracterizar a atividade atual de trabalho dos participantes, evidenciando os impedimentos e estratégias de superação. Para os propósitos deste artigo, são descritos os impedimentos e suas estratégias de superação.

Um exemplo de impedimento real foi trazido na fotografia do P1. Ele relata que seu colega de sala deveria repassar as atribuições e ensinar a usar os sistemas de informação da instituição e as demais atividades do setor. Entretanto, ele afirma que o colega não ensinou, e fica postergando há meses as informações que ele precisa saber para executar as atividades. O P1 observa que a situação já foi relatada ao chefe, porém, nada foi feito. O resultado é a quase completa ociosidade de P1 durante seu horário de trabalho. A Figura 1 explicita tal situação.

Figura 1 - O trabalho esvaziado

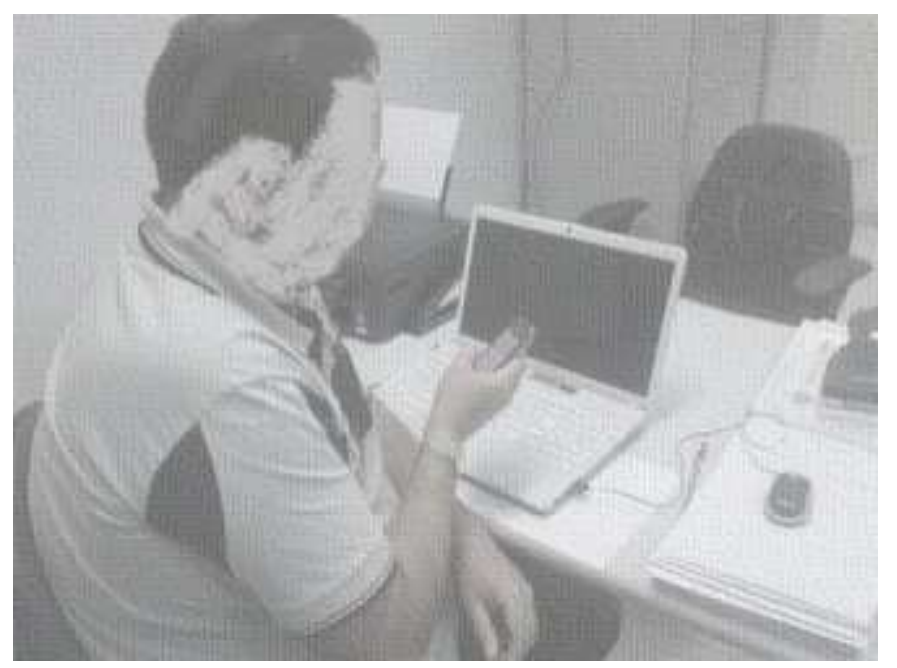

A fotografia mostra P1 com o computador aberto, porém desligado, jogando no celular, já que não tem outra coisa para fazer. Ele conta que passa horas assim, e que na maior parte do tempo ele faz atividades simples, como organizar as correspondências que chegam, assinar o recebimento de documentação, tirar uma fotocópia, enviar algum documento via e-mail. Sua tarefa prescrita era de que ele resolveria todas as pendências acadêmicas do sistema de informações - ou seja, teoricamente teria muito trabalho; contudo, sua atividade concreta não é como a prevista. Em suas palavras:

Fico aqui o dia inteiro no computador, simplesmente pagando expediente. ... Aí eu fico aqui sem fazer nada, eu não estou acostumado a ficar sem fazer nada. Eu estou acostumado a trabalhar mesmo, não vim pra cá pra ficar enrolando. (P1) 
A atividade tem um papel fundamental para a constituição psicológica do sujeito. É na atividade concreta que o sujeito atribui sentidos e significados à sua experiência com o mundo, objetivando e subjetivando essa realidade num processo dialético (Maheirie, 2002). Nesse sentido, a atividade de trabalho é mais que um emprego que garante renda: é uma forma de ser no mundo (Clot, 2008).

A atividade do P1 estava sendo amputada, impedida, e ele nada conseguia fazer a não ser esperar e acreditar que, com o tempo, algo iria mudar. Tal como Clot (2010) afirma, o resultado dessa amputação da atividade é o adoecimento (físico e/ou psicológico). De fato, O P1 relatou que tinha que se ausentar várias vezes por indisposição causada por suas deficiências e por "desgosto" com aquela ida sem sentido ao trabalho todos os dias para nada fazer.

O único caso em que a fotografia elencou diretamente elementos sobre a deficiência foi nas imagens e relatos do P6. Ele foi 0 participante cujas condições de deficiência eram mais graves, pois se tratava de uma perda progressiva e sem cura da visão. Suas fotografias foram sempre relacionadas à sua deficiência, apresentando pontos positivos e negativos que ele registrou. Com relação aos impedimentos, o P6 trouxe uma fotografia ilustrando um ponto negativo, retratando-o num esforço para tentar enxergar o que está escrito num papel, como explicita a Figura 2.

Figura 2 - Os impedimentos (in)visíveis

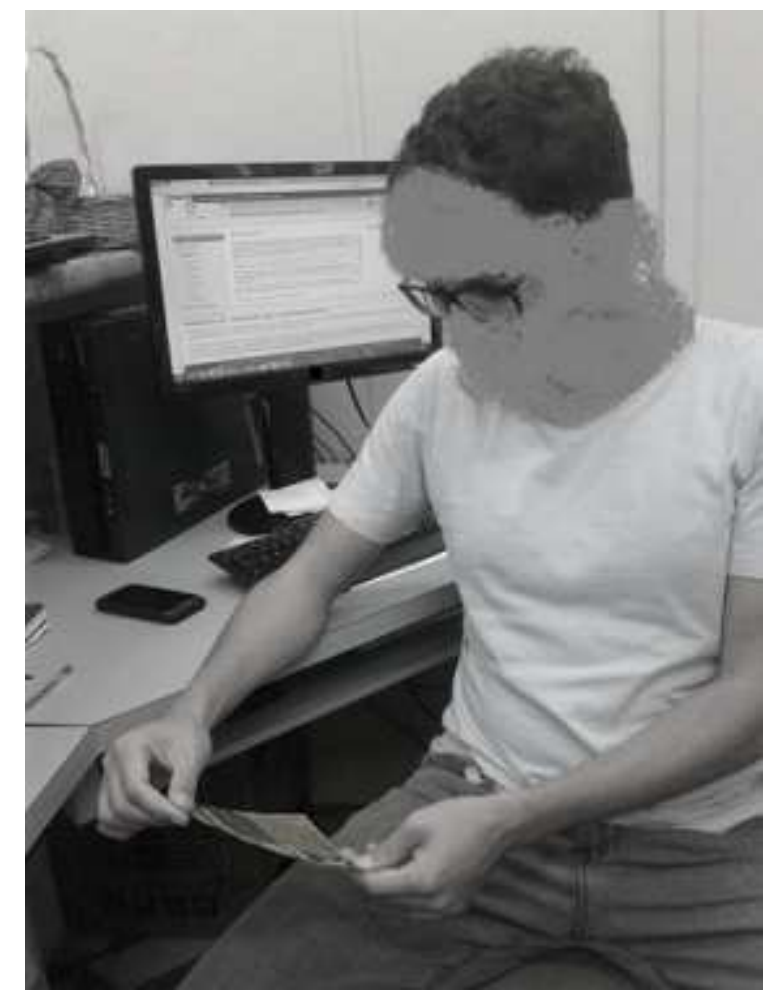


Suas dificuldades visuais se configuram como um impedimento para realização de algumas atividades, e suas estratégias para lidar com isso envolvem pedir ajuda para seus colegas de trabalho, os quais são fundamentais para que ele possa cumprir com as tarefas diárias em tempo hábil. Segundo o P6:

As minhas limitações hoje são pequenas, são poucas. Às vezes eu tenho que pedir ajuda a alguém para poder fazer alguma coisa, às vezes um simples bilhete escrito a lápis, eu não consigo ler. (P6)

A ajuda que ele precisa dos colegas muitas vezes se resume à compreensão de que não adianta escrever a lápis grafite, pois ele só consegue enxergar coisas escritas à caneta. Não conseguir realizar as suas atividades e saber que seu quadro só piora deixa P6 sem esperança, e isso, em sua visão, o faz adoecer. Ele afirmou que já teve depressão, mas o fato de ter conseguido passar no concurso e estar trabalhando the deu ânimo novo. Quando se depara com coisas que não consegue fazer, papeis que não consegue ler e não obtém ajuda, se sente impotente, e às vezes fica triste pensando sobre isso. Por fim, a fotografia de do P7 traz, como um dos maiores impedimentos a seu trabalho, a tentativa de outras pessoas em calarem sua voz. Em meio às explicações sobre a sua atividade de técnico de enfermagem, fala da dificuldade de relacionamento com alguns profissionais e, principalmente, chefias que ele tem que lidar. O relato é sobre humilhações de alguns profissionais hierarquicamente superiores no contexto de trabalho e a reação dele diante disso. A Figura 3 retrata o P7 com a mão em sua boca de modo que ele não possa falar.

Figura 3 - As vozes caladas

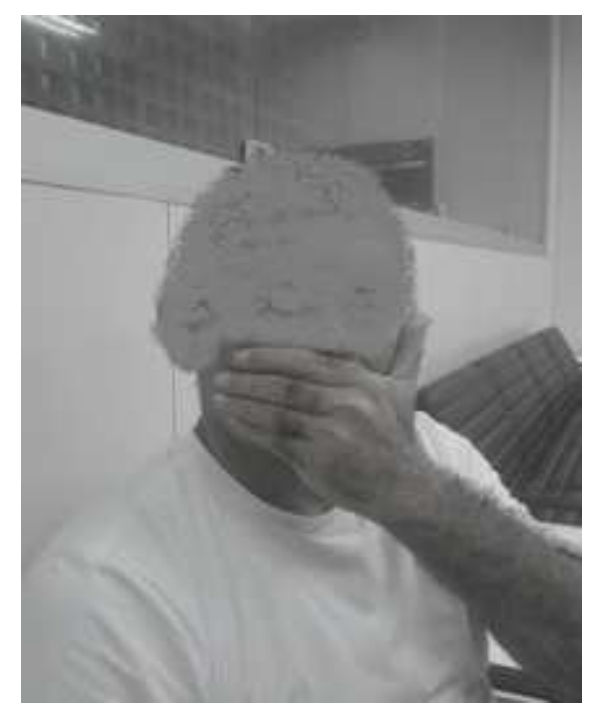


Segundo a fala do P7:

Eu tenho voz, eu tenho vida, não vou me calar diante deles não, eles tem que conversar e falar comigo como uma pessoa, todos tomos pessoas, somos humanos, e eles podem até mandar eu me calar, mas no dia que eu não tiver voz, que eu ficar calado, eu terei morrido. (P7)

No caso de $\mathrm{P7}$, seu maior impedimento é causado pela deterioração do relacionamento com superiores que, segundo ele, menosprezam suas opiniões e são grosseiros quando falam com ele. Ainda segundo P7, ele não consegue mensurar ao certo se essa hostilidade se relaciona com sua deficiência ou com sua baixa hierarquia no setor de trabalho. E, sua estratégia para superar esse impedimento é a partir do enfrentamento, não cedendo às pressões para calar sua voz.

\section{Considerações finais}

Tendo em vista o objetivo de pesquisa de identificar, ao longo da biografia profissional, os sentidos e significados atribuídos ao trabalho, e o modo como eles se relacionam com a percepção de deficiência, pode-se afirmar que, em especial a categoria "significado", parece não diferir dos significados do trabalho indicados na literatura junto a outros grupos populacionais. Isso talvez tenha a ver com a própria natureza desse constructo (significado): ser mais estável e socialmente compartilhado. Assim, nesta pesquisa, constatamos que o trabalho é visto pelos participantes como necessidade, como prazer e realização, como meio que possibilita o desenvolvimento de relações pessoais. Ou então o trabalho como fonte de aprendizado e busca por posição estável representada pelo serviço público. Todas essas características são frequentemente associadas ao trabalho (e.g.: Graf \& Coutinho, 2011; Pereira, Del Prette, \& Del Prette, 2008).

Quanto aos sentidos do trabalho, e sua relação com a deficiência, nota-se igualmente pontos de convergência entre os participantes, embora cada um o tenha expressado de modo singular, como é previsto pela própria perspectiva teórica aqui adotada. A deficiência não parece, nos relatos apresentados, ser um elemento capaz de provocar uma "ruptura" na percepção de si mesmo no trabalho, a ponto de a pessoa sentir-se radicalmente diferente das demais. Isso se observa com respeito aos relatos de superação, de afirmação de si perante o trabalho. A deficiência, embora isso dependa do grau de severidade, é interpretada como mais um desafio que se tem de 
superar, juntamente a outros desafios que, de acordo com os participantes, são inerentes ao próprio trabalhar.

Os sentidos do trabalho estão inextricavelmente ligados à biografia dos participantes. A história de cada um faz com que os significados socializados culturalmente sobre o trabalho sejam capturados com tonalidades afetivas próprias. Assim, o sentido de "superação" dado por um pode ter conotações diferentes do sentido dado por outros, haja vista as diferenças nas trajetórias biográficas dos participantes aqui pesquisados, mas que, por razões de espaço, não puderam ser apresentadas. Para um, a superação tem a ver com a possibilidade de trabalhar de igual para igual com outros "sem deficiências" no trabalho; para outro, tem a ver com a conquista de um lugar na sociedade, a despeito de condições biográficas adversas ou de um passado pessoal desfavorável antes de se alcançar o emprego no serviço público. Mas, tanto num caso como no outro, trata-se de interpretações a partir da "representação coletiva" (significados) do trabalho como atividade voltada à transformação de si, da realidade, e dos outros.

Considerando o segundo objetivo específico pesquisado, de descrever os impedimentos da atividade de trabalho real (concreta) vivenciados pelos participantes, e as estratégias desenvolvidas para sua superação, é possível afirmar que a técnica da criação fotográfica demonstrou que os principais impedimentos foram: a incompreensão de colegas de trabalho que se recusavam a repassar as tarefas e atividades de trabalho; as condições materiais ausentes ou ineficazes para a realização do trabalho; a falta de condições ambientais para a realização das atividade; e dificuldades relacionadas a se pronunciar em situações grupais. As estratégias de superação variaram entre impotência diante da situação, com amputação do poder de agir, tentativa de criar meios alternativos para suprir as necessidades dos materiais, e não calar-se diante de uma atitude abusiva da chefia.

Novamente, considera-se que as situações de impedimento e superação descritas acima podem estar presentes em quaisquer outros contextos e com pessoas sem qualquer tipo de deficiência. Assim, a deficiência, apesar de geradora de dificuldades na realização da atividade de trabalho, aparece como um impedimento superável, que não inviabilizava a realização da atividade, mas que demanda alguns esforços adicionais da pessoa e dos seus pares, bem como do auxílio de tecnologias adaptativas, como no caso do P8, que, quando seu aparelho auditivo quebrava, se comunicava com seus clientes pela internet. Os achados sugerem que os impedimentos, apesar de não advirem, necessariamente, das deficiências, podem se revelar fator de adoecimento, tal como defendem os estudos de Clot (2010, 2008) com respeito ao trabalho em geral, independentemente da condição específica da pessoa. 
Quando o sujeito sente estar cumprindo com sua função social por meio do trabalho, e se sente integrado às demais pessoas e se desenvolvendo, isso parece fazer com que a experiência laboral adquira uma nuance de significação positiva para os participantes desse estudo. Nesse sentido, o trabalho funciona como uma categoria que propicia vivências sociais de inclusão, reforçando o papel positivo da reserva de vagas em contextos laborais de acesso dificultado para as pessoas com deficiências, como demonstrado aqui e corroborado em outras pesquisas (e.g., Carvalho-Freitas, 2007; Sassaki, 2002). Segundo Zanitelli (2013). A lei reserva de vagas ainda tem muito a melhorar, especialmente em relação a seu cumprimento efetivo, mas, sem nos determos nas questões legais envolvidas, pode-se afirmar que, para os participantes dessa pesquisa, a referida lei desempenhou um papel importante.

O fato de a pesquisa ter sido realizada com servidores, numa instituição pública de ensino, traz luz sobre um perfil diferenciado de pessoas com deficiências, não retratando a realidade brasileira, já que, em comparativo aos dados do Censo (2010) sobre essa população, os participantes dessa pesquisa se sobressaem em termos de escolaridade e salário. De modo que os sentidos e significados, por levarem em conta as vivências dos sujeitos, certamente são influenciados por tal contexto e não devem ser motivo de generalização para todo o contingente de pessoas com deficiências.

Uma reflexão final sobre a relação entre o conceito de impedimento e a categoria sentido. O sentido move a atividade: enquanto há sentido, há a continuidade da atividade, ainda que seja uma atividade impedida, que possa acarretar adoecimento para o sujeito. O sentido se faz presente ainda que haja esvaziamento da atividade, amputação do poder de agir e sofrimento de um modo geral, pois o sentido é o mecanismo que justifica a existência da ação do sujeito diante da atividade. Se não houver sentido, ainda que externo à atividade, mas que de alguma maneira a justifique, não há atividade. Dessa forma, um impedimento não configura, necessariamente, uma situação limite, sem saída, pois mesmo uma situação "sem saída" é plena de sentidos.

Em termos de perspectivas futuras, essa pesquisa abre o leque para que sejam investigados, a partir da mesma perspectiva sóciohistórica, se a deficiência seria um fator de impedimento no trabalho nos casos em que as deficiências fossem severas. Como alternativa metodológica, as fotografias se mostraram ricas, e abrem oportunidades para se pensar em estudos longitudinais, de modo a acompanhar, como um "álbum de fotos", as principais ocorrências da atividade de trabalho. Finalmente, esse estudo se delineia por um viés específico para compreender o fenômeno da inclusão: a perspectiva dos sentidos/significados e impedimentos. Quanto a estes últimos, e de acordo com Monteiro, Oliveira, Rodrigues e Dias (2011), 
grande parte da responsabilidade para que haja a inclusão das pessoas com deficiências está no papel das empresas. Porém, estas nem sempre podem ou estão dispostas a implementar as adaptações/mudanças necessárias (Brunstein \& Serrano, 2008).

\section{Referências}

Aguiar, W. M. J., \& Ozella S. (2006). Núcleos de significação como instrumento para a apreensão da constituição dos sentidos. Psicologia Ciência e Profissão, 26(2), 222-245.

Aguiar, W. M., \& Ozella, S. (2013). Apreensão dos sentidos: aprimorando a proposta dos núcleos de significação. Revista Brasileira de Estudos Pedagógicos, 94(236), 299-322.

Barros, J. P. P., Paula, L. R. C., Pascual, V. F. R., \& Ximenes, V. M. (2009). O conceito de "sentido" em Vygotsky: considerações epistemológicas e suas implicações para a investigação psicológica. Psicologia \& Sociedade, 21(2), 174-181.

Bendassolli, P. F. (2012). Psicologia do trabalho como psicologia da ação: O aporte das teorias da atividade. Psico (PUCRS. Online), 43(3), 341-349.

Borges, L. O. (1999). A estrutura fatorial dos atributos valorativos e descritivos do trabalho. Estudos de Psicologia, 4(1), 107-139.

Brunstein, J., \& Serrano, C. A. (2008). Vozes da diversidade: um estudo sobre as experiências de inclusão de gestores e PcDs em cinco empresas paulistas. Cadernos EBAPE.BR, 6(3), 01-27.

Carvalho-Freitas, M. N. (2007). A inserção de pessoas com deficiência em empresas brasileiras. Tese de Doutorado, Universidade Federal de Minas Gerais, Belo Horizonte, MG, Brasil.

Ciszewski, A. C. V. de O. (2005). O trabalho da pessoa portadora de deficiência. São Paulo, LTr.

Clot, Y. (2008). Trabalho e poder de agir. Paris: PUF.

Clot, Y. (2010). A psicologia do trabalho na França e a perspectiva da clínica da atividade. Fractal: Revista de Psicologia, 22(1), 207234.

Creswell, J. W. (2007). Projeto de pesquisa: métodos qualitativo, quantitativo e misto. 2. ed. Porto Alegre: Artmed, 2007.

Figueira, E. (2008). Caminhando em silêncio. Giz Editorial, São Paulo.

França, I. S. X. de, \& Pagliuca, L. M. F. (2009). Inclusão social da pessoa com deficiência: conquistas, desafios e implicações para a enfermagem. Revista da Escola de Enfermagem da USP, 43(1), 178-185.

Galvão, M. (2005). Narrativas em educação. Ciência \& Educação, $11(2), 327-345$. 
Graf, L. P., \& Coutinho, M. C. (2011). Desvelando sentidos no trabalho de mulheres na produção avícola. Aletheia, (35-36) 95-108.

IBGE - Instituto Brasileiro de Geografia e Estatística (2010). Censo demográfico: resultados preliminares. Brasil.

Lei n. 8.213, 24 de julho de 1991. Art.93. (1991). Dispõe sobre os planos de benefícios da previdência social e dá outras providências. Brasília. Recuperado em 14 de fevereiro, 2013, de http://www.planalto.gov.br/ccivil_03/Leis/L8213cons.htm

Leontiev, A. N. (1978). Atividade consciência e personalidade. Buenos Aires: Edições Ciências do Homem.

Maheirie, K. (2002). Constituição do sujeito, subjetividade e identidade. Revista Interações, VII(13), 31-44.

Marx, K. (1983). O capital. Rio de Janeiro: Zahar editores S.A. (Originalmente publicado em 1867).

Maurente, V., \& Tittoni, J. (2007). Imagens como estratégia metodológica em pesquisa: a fotocomposição e outros caminhos possíveis. Psicologia \& Sociedade, 19(3), 33-38.

Meaning of Work Research Team. (1987). The meaning of working. San Diego, CA: Academic Press.

Monteiro, L. G., Oliveira, S. M. Q. de, Rodrigues, S. M., \& Dias, C. A. (2011). Responsabilidade social empresarial: inclusão de pessoas com deficiência no mercado de trabalho. Revista Brasileira de Educação Especial, 17(3), 459-480.

Morin, E. (2001). Os sentidos do trabalho. Revista de Administração de Empresas, 41(3), 8-19.

Morin, E. (2006). Donner un sens au travail. Montréal, Quebec, Canada: HEC.

Morin, E. (2007). Sens du travail, santé mentale au travail et engagement organisationnel. Cahier de Recherche, 543, 99193.

Namura, M. R. (2004). Por que Vygostsky se centra no sentido: uma breve incursão pela história do sentido na psicologia. Psicologia Educacional, 19, 91-117.

Osório, C., \& Maia, M. (2010). Fotografias co-produzidas da situação de trabalho: imagens em ato da atividade em saúde. Informática na Educação: Teoria \& Prática, 13(2), jul./dez.

Pereira, C. de S., Del Prette, A., \& Del Prette, Z. A. P. (2008). Qual o significado do trabalho para as pessoas com e sem deficiência física? Psico-USF, 13(1), 105-114.

Sassaki, R. K. (2002). Inclusão: construindo uma sociedade para todo. Rio de Janeiro: WVA.

Schütze, F. (2007). Biography analysis on the empirical base of autobiographical narratives. Recuperado em 01 de maio, 2013, de: 
http://www.unimagdeburg.de/zsm/projekt/biographical/1/B2.1. pdf

Silva, O. M. (1987). A epopeia ignorada: a pessoa deficiente na história do mundo de ontem e de hoje. São Paulo: CEDAS.

Smolka, A. L. B. (2004). Sobre significação e sentido: Uma contribuição à proposta de redes de significação. In M. C. Rossetti-Ferreira, K. S. Amorin, \& A. P. S. Silva (Orgs.). Redes de significações: alguns conceitos básicos (pp.35-49). Porto Alegre: Artmed.

Tolfo, S. R., \& Piccinini, V. (2007). Sentidos e significados do trabalho explorando conceitos, variáveis e estudos empíricos brasileiros. Psicologia \& Sociedade, 19(edição especial), 38-46.

Vygotsky, L. S. (1896/2008). Pensamento e linguagem. São Paulo: Martins Fontes.

Vygotsky, L. S. (1924/2011). A defectologia e o estudo do desenvolvimento e da educação da criança anormal. Educação e Pesquisa, 37(4), 863-869.

Wisner, A. (1996). Questões epistemológicas em ergonomia e em análise do trabalho. Em: F. Daniellou (Org.). A ergonomia em busca de seus princípios (pp. 29-55). São Paulo: Blucher.

Zanitelli, L. M. (2013). A lei de cotas para pessoas portadoras de deficiência nas empresas brasileiras: impacto e possíveis alternativas. Ciência \& Saúde Coletiva, 18(7), 2085-2094.

\section{Endereço para correspondência \\ Juliana Cavalcante Marinho Paiva}

Universidade Federal do Rio Grande do Norte

Departamento de Psicologia

Av. Senador Salgado Filho, s/n, Campus Universitário, CEP 59078-970, Natal - RN, Brasil

Endereço eletrônico: jc_julianac@yahoo.com.br

Pedro F. Bendassolli

Universidade Federal do Rio Grande do Norte

Departamento de Psicologia

Av. Senador Salgado Filho, s/n, Campus Universitário, CEP 59078-970, Natal - RN, Brasil

Endereço eletrônico: pbendassolli@gmail.com

\section{Camila Costa Torres}

Universidade Federal do Rio Grande do Norte

Departamento de Psicologia

Av. Senador Salgado Filho, s/n, Campus Universitário, CEP 59078-970, Natal - RN, Brasil

Endereço eletrônico: pcamilatorres@gmail.com

Recebido em: 29/10/2014

Reformulado em: 03/03/2015

Aceito para publicação em: 04/03/2015

Notas 
* Mestranda da Pós-graduação em Psicologia da Universidade Federal do Rio Grande do Norte/UFRN - Rio Grande do Norte, RN, Brasil.

** Professor Adjunto no Departamento de Psicologia da Universidade Federal do Rio Grande do Norte. Doutor em Psicologia Social pela USP.

*** Professora Adjunta no Departamento de Psicologia da Universidade Federal do Rio Grande do Norte. Doutora em Psicologia pela Universidade de Brasília. 